\title{
Simulation of columnar transfer and retention of Escherichia coli bio-pollutant index in a saline saturated soil
}

\author{
Sahar Akhavan ${ }^{1}$, Soheila Ebrahimi ${ }^{2 *}$, Ali Mojtahedi ${ }^{3}$, Maryam Navabian $^{4}$, Mahmoud Shabanpour ${ }^{5}$, \\ Alireza Movahedi Naeini ${ }^{6}$ \\ ${ }^{1}$ Ph.D Student,Department of Soil Sciences, School of Agriculture Gorgan, \\ University of Agricultural Sciences and Natural Resources, Gorgan, Iran \\ ${ }^{2}$ AssistantProfessor, Department of Soil Sciences, School of Agriculture Gorgan, \\ University of Agricultural Sciences and Natural Resources, Gorgan, Iran \\ ${ }^{3}$ AssistantProfessor, Department of Medical Sciences, School microbiology, \\ Guilan University, Guilan, Iran \\ ${ }^{4}$ AssistantProfessor, Department of agriculture, School Water Engineering, \\ Guilan University, Guilan, Iran \\ ${ }^{5}$ Associate Professor, Department of agriculture, School Soil Engineering, \\ Guilan University, Guilan, Iran \\ ${ }^{6}$ Associate Professor, Department of Soil Sciences, School of Agriculture Gorgan, \\ University of Agricultural Sciences and Natural Resources, Gorgan, Iran
}

\begin{abstract}
Today, microbial contamination of surface waters and groundwater is a serious health problem that can lead to dangerous diseases. In this research, the transmission and retention of Escherichia coli bacteria (E. coli) was simulated as an index of groundwater pollution in soil saturation conditions, considering the importance of preferential flow using synthetic macropores (different diameters of macropores including 0,1 and $2 \mathrm{~cm}$ ) and using HYDRUS-2D model.Also, the effect of different salinity levels of water (including electrical conductivity of 1,2 and $4 \mathrm{dSm}^{-1}$ ) on the transmission of E. coli bacteria was investigated. Thepreferential flow system was prepared and designed using two sand size including fine sand and coarse sand in the columns. The results showed that the retention of $E$. coli increased with the ionic strength of the solution, while the effect of E. coli in the fine sand was greater than that of coarse sand. This bacterial transfer behavior was well described by numerical simulations. The importance of preferential flow in bacterial transfer showed that it increases at higher ionic strength, even if overall transmission is reduced. Although the bacterial transmission is facilitated in salinity, the results of this study showed that an increasing in ionic strength of the soil solution increased the amount of bacterial purification that could be effective in controlling groundwater contamination with saline water management.
\end{abstract}

Keywords: Transfer, Escherichia coli bacteria, pollution, Hydrous-2D model

\section{Introduction}

Today, microbial contamination of surface waters and groundwater is a serious health problem that can lead to dangerous diseases. Reaching this bio-pollutant to water resources is mainly due to human activities such as household, municipal and hospital wastes, waste disposal sites, wastewater wells, animal waste and animal fertilizers (Jackwood, 2013). Soil seems to act as a filter and prevent bacteria from entering groundwater, but it is an heterogeneous media that has fine and coarse pores, and it has preferential flow mainly due to the wormholes, the space between the aggregates, the channels left from the decayed roots of the plants or cracks in the clay soils that promotes the rapid transfer of bacteria in the soil (Simonck et al., 2003).

Today, the use of alternative sources, especially unconventional water such as drainage waters from farms, saline water and surface and underground waters, has been seriously raised due to the growing restrictions of fresh water resources and consequent reduction of quality and land fertility. Although the application of saline water shows a significant difference compared with non-saline water conditions, there are some options for the continuity and stability of agricultural activities, in order to provide a suitable bed for their sustainable consumption (Feng et al., 2017).Salinity is one of the important stressors for microorganisms. Decreased respiration, reduced carbon dioxide levels, decreased enzymatic activity, and decreased microbial biomass are occurred due to salinity (Mamilo et al., 2004). The factors influencing the reaction of the bacteria with the surface of the sand are surface load change and hydrophobic properties (Wang, 2013). Also, surface absorption affects cell surface load, hydrophobicity, size and lipopolysaccharide surface structure (LPS) of the outer cell of E.coli. It is due to this fact that E.coli liposaccharide is themain factor in its absorption onto the mineral surfaces, absorption of metal ions and microbial stimuli, and sedimental reactions and dissolution. 
Liposaccharide contains a phosphoric oligosaccharide hydrophobic fat and polysaccharide which, due to its low hydrophobic contact angle, leads to weak adhesion of E.coli (Foppenand Schijven, 2006).Also, various studies have shown that the main reason for the transfer of bacteria in undisturbed soils is preferential flows due to the continuity of coarse pores and cracks in the soil. During the transfer of bacteria, the presence of macropores and bio-pores allows fertilizer wastewater and microorganisms to quickly pass the soil matrix and reach to deeper soils and possibly to subsurface drainage systems (Wang et al., 2014).

In order to investigate the transfer of studiedbio-pollutant, use of models in predicting its movement in soil can save considerable time and cost. But these predictions are useful and practical when the accuracy and validity of the model in these estimations are investigated. This means that, first, according to observational data, first the model parameters are optimized which requires controlled conditions. Therefore, it is essential to carry out research in the field of model evaluation in precise laboratory and controlled conditions before it can be used in natural conditions (Farokhian et al., 2015). The Hydrus-2D software model has been developed to simulate the two-dimensional movement of water, heat and solvents in a porous medium and different humidity conditions. This model uses Richard equations and flux-diffusion to explain the motion of water and solutes (Simuneket al., 1999). The absorption coefficients of bacteria increased with clay content. The balanced and symmetrical shape of the breakthrough curves of the soil columns showed that leaching mainly occurred through the matrix flow (Safadoust et al., 2012). Wang et al, (2014) was able to accurately describe the precise transfer of E. coli in the column with the status and length of different synthetic macropores at two levels of ionic strength $(1$ and $20 \mathrm{mM}$ $\mathrm{NaCl}$ )using the dual-permeability model of HYDRUS software, by optimizing the absorption parameters of the bacterium. The results showed that decreasing macropores length reduced the apparent saturation hydraulic conductivity in the macroporous range. Also, the length of synthetic macropores has greatly influenced the preferential transmission of Escherichia coli, especially in high ionic strength conditions. In low ionic strength, a wider transmission in the preferred pathway and an earlier time to reach Escherichia coli than bromide was observed as a result of the size limitation (Wang et al., 2014b). In another study, Unc and Goss (2003), using modeling with HYDRUS, reported that the estimation of the migration rate of bacteria in the soil profile was consistent with the major hypothesis of bacterial transmission from macropores. The transfer rate of the bacteria was faster than the rate of water transfer in the soil pores. Suspended bacteria pass faster through the larger diameter of the pores and water in the pores (Unc and Goss, 2003).

\section{Materials and Methods}

In the present study, the transfer and retention of Escherichia coli in a preferential flow system with synthetic macropores (different macropores diameters including 0,1 and $2 \mathrm{~cm}$ ) and different water salinity (including electricalconductivity of 1,2 and $4 \mathrm{ds} \cdot \mathrm{m}^{-1}$ ) under saturation flow in experimental soil columns at the year of 2016 was studied.Preferential flow experiments were carried out in PVC containers with specific lengths and inner diameters (20 and $10 \mathrm{~cm}$, respectively). After measuring some of the early soil properties (Table 1), the preferential flow system was prepared and designed using two sand types including fine sand and coarse sand in the columns. To prepare the soil columns, first about one third of the height of the columnwas filled with distilled water (autoclaved) and a plastic tube with a diameter of $30 \mathrm{~cm}$ with a desired diameter $(1$ and $2 \mathrm{~cm})$ was placed in the center of the column. The fine sand was gradually added to the column matrix (outside of the plastic tube). Then, the extra water in the plastic tube was drained from the bottom. Then, the tube was carefully drawn out of the column without disturbance around the sand structure, leaving a hole with a diameter of $2 \mathrm{~cm}$ in the center of the column. At this stage, the hole was filled up to a depth of 20 centimeters with coarse sand using a funnel to create the macropore structure of the desired preferential flow. A thin layer of coarse sand was placed on the surface of the soil column to prevent from the destruction of the soil structure (Fig. 1). At the end,the column was saturated with water from the bottom to control the downstream pressure at zero centimeters. The desired solutions were added from the upper boundary of the heterogeneous column at a constant flow rate. The column was saturated during the experiment with maintaining the surface depth of less than five centimeters.

Table 1. Primary characteristics of the soil of the experimental columns

\begin{tabular}{ccccccccc}
\hline Material & Soil Texture & $\begin{array}{c}\mathrm{EC} \\
\left(\mathrm{dsm}^{-1}\right)\end{array}$ & $\begin{array}{c}\mathrm{pH} \\
(1: 2)\end{array}$ & $\begin{array}{c}\text { Bulk density } \\
\left(\mathrm{gr.cm}^{-3}\right)\end{array}$ & $\begin{array}{c}\text { Moisture } \\
(\%)\end{array}$ & $\begin{array}{c}\text { Clay } \\
(\%)\end{array}$ & $\begin{array}{c}\text { Silt } \\
(\%)\end{array}$ & $\begin{array}{c}\text { Sand } \\
(\%)\end{array}$ \\
\hline Macropore & Loamy Sand & 0.7 & 7.1 & 1.6 & 15 & 10 & 10 & 80 \\
Matrix & Sandy Loam & 0.76 & 7.1 & 1.4 & 20 & 8 & 16 & 76 \\
\hline
\end{tabular}



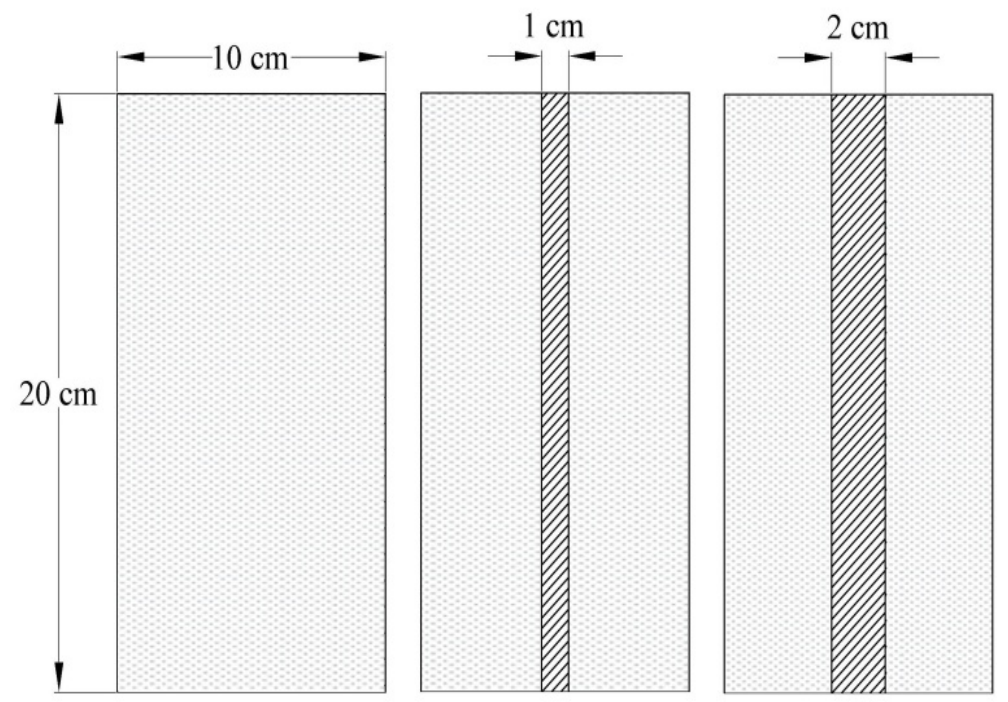

Figure 1 - Schematic representation of the 3 types of macropore structure that was studied in this study: type 0 ) homogeneous fine sand;type 1) macropore with a diameter of $1 \mathrm{~cm}$ in the center of the column; type 2) macropore with a diameter of $2 \mathrm{~cm}$ in the center of the column. (It shows the diagonal pattern of coarse sand and the point pattern of fine sand).

Before starting the microbial transfer test, two pore volumes (PV) of $\mathrm{NaCl}$ solution (saline treatment) were selected and were added tosterilized columns using sterilized physiology serum and allowed the sand to reach a balance statue with the solution (phase 0). Microbial transfer experiments were carried out in two phases with boundary conditions and flow velocity,similar to phase 0 . First, a pulse of microbial suspension was added to the column at a constant velocity (phase 1). Then a $\mathrm{NaCl}$ solution in the column was added with flow rate and ionic strength similar to phase 1 until the concentration of the microbial wastewater was returned to the initial amount (Phase 2). Escherichia coli suspension was sprayed uniformly at the top of the sterile soil column along the flame using sterile syringe. The bacterial suspension was prepared by McFarland Turbidity Standard by mixing of $1.175 \%$ barium chloride dehydrate $(0.048 \mathrm{M})$, with $9.95 \mathrm{~mL}$ of $1 \%$ sulfuric acid $(0.36 \mathrm{~N})$. Washing of soil columns continued for one hour and wastewater samples were collected from the bottom of the column at times of $0,1,2,3,5,7,10,12,15,20,25,35,40,45,50,60$ minutes. The experiment was performed with three replications for each treatment. Then bacterial concentrations were analyzed. The drained bacterial suspensions were prepared with dilutions of $10^{-1}, 10^{-2}$ and $10^{-3}$. After dilution of the samples, $0.1 \mathrm{ml}$ of the diluted solution was cultured in EMB plates. The bacterial concentrations in the effluent were estimated by the number of E.coli plates in EMB agar after $24 \mathrm{~h}$ incubation at $37^{\circ} \mathrm{C}$, and then the concentration of the bacteria in the drained water was calculated and expressed with theunit of colony in milliliters (CFU ml $\left.{ }^{-1}\right)($ Connie et al, 2011).

In order to measure the bacteria in the soil profile, after the end of the bacterial transfer experiment, the soil column was divided into three layers. The samples were taken from three depths and the samples were taken at each depth from two macropores and matrix areas. One gram of each sample was added to a $15 \mathrm{~mm}$ centrifuge tube with a $9 \mathrm{~mL}$ solution of $0.2 \%$ Calgon (sodium hexametaphosphate). For isolation of the bacteria in the liquid phase from the solid phase, each sample was mixed in a vortex mixer for 15 minutes. To determine the concentration of bacteria in the uppermost solution, live counting method was used (Kenney et al., 2011). The bacterial counting in the soil profile was done by measuring the concentration of bacteria in the wastewater.

\section{Sensitivity Analysis of the model}

Investigating the effect of changes in input data on output data is known as sensitivity analysis. To determine the sensitivity coefficient of the input parameters of the model, the method of Liu et al (2007) was used:

$$
\mathrm{S}_{\mathrm{c}}=\frac{\frac{\Delta \mathrm{W}}{\mathrm{W}}}{\frac{\Delta \mathrm{P}}{\mathrm{P}}}(1)
$$

Where, $\mathrm{S}$ is the sensitivity coefficient, $\Delta \mathrm{W}$ is the difference in the output parameter before and after the input data change, $\overline{\mathrm{W}}$ is the average of output parameter before and after the input data change, $\Delta \mathrm{P}$ is the difference between the input value of a parameter to the model, and $\bar{P}$ is the average input value of a parameter to the model. 
The values of the sensitivity coefficient of the model for simulating the transfer of E. coli bacteria in the water movement and transfer bacteria are presented in Table (2). The results showed that the most sensitive input parameters of the model were saturation moisture content $(\theta \mathrm{s})$ and saturated hydraulic conductivity (Ks). In fact, the model is sensitive to changes in these parameters, and the change in these parameters is effective on the simulation process. The parameter of inverse of air entry potential into the soil was insensitive in the humidity curve $(\alpha)$, that is, the model was not sensitive to changes in this parameter and the change in this parameter did not affect the simulation process. The distortion factor (1) had a low sensitivity. Parameters of water diffusion, residual moisture, longitudinal and transverse diffusion coefficients had moderate sensitivity.

Table 2. The sensitivity coefficients of input parameters

\begin{tabular}{ccccccccc}
\hline Parameter & $\theta_{\mathrm{r}}$ & $\theta_{\mathrm{s}}$ & $\mathrm{K}_{\mathrm{s}}$ & $\alpha$ & 1 & DIFW $\left(\mathrm{cm}^{2} /\right.$ day $)$ & DISPT $(\mathrm{cm})$ & DISPL $(\mathrm{cm})$ \\
\hline $\mathrm{Sc}$ & 1.7 & 2.5 & 2.1 & 0 & 0.2 & 1.9 & 1.5 & 1.7 \\
\hline
\end{tabular}

\section{Transmission of bacteria}

The general equation governing the absorption and transfer of bacteria in the soil was expressed by the two-site kinetic attachment-detachment model (Schijven, J. and J. Šimůnek. 2002). This model describes the attachmentdetachment processes with a first-order kinetic process. The kinetic absorption yieldconsists of two steps. In the first step, the so-called mass transfer, the bacteria is transferred from the liquid phase to the particle surface. In the second step, the bacteria are absorbed on the soil particle surface by the physical and chemical interactions. In a two-dimensional mode, the kinetic attachment-detachment model expresses the transfer of colloidal particles, bacteria and viruses as follows:

$\frac{\rho_{\mathrm{b}}}{\theta} \frac{\partial \mathrm{S}_{1}}{\partial \mathrm{t}}=\mathrm{k}_{\mathrm{att} 1} \mathrm{C}-\mathrm{k}_{\operatorname{det} 1} \frac{\rho \mathrm{b}}{\theta}-\mu_{\mathrm{s}} \rho_{\mathrm{b}} \mathrm{S}_{1} 2$

$\frac{\rho_{\mathrm{b}}}{\theta} \frac{\partial \mathrm{S}_{2}}{\partial \mathrm{t}}=\mathrm{k}_{\mathrm{att} 2} \mathrm{C}-\mathrm{k}_{\mathrm{det} 2} \frac{\rho \mathrm{b}}{\theta}-\mu_{\mathrm{s}} \rho_{\mathrm{b}} \mathrm{S}_{2} 3$

$\frac{\partial \mathrm{C}}{\partial \mathrm{t}}+\frac{\rho_{\mathrm{b}}}{\theta} \frac{\partial \mathrm{S}_{1}}{\partial \mathrm{t}}+\frac{\rho_{\mathrm{b}}}{\theta} \frac{\partial \mathrm{S}_{2}}{\partial \mathrm{t}}=\mathrm{D} \frac{\partial^{2} \mathrm{C}}{\partial \mathrm{z}^{2}}-\mathrm{v} \frac{\partial \mathrm{C}}{\partial \mathrm{z}}-\mu_{1} \mathrm{C}-\mu_{\mathrm{s}} \rho_{\mathrm{b}}\left(\mathrm{S}_{1}+\mathrm{S}_{2}\right) 4$

where, $\mathrm{C}$ is the concentration of bacteria in the liquid phase $\left(\mathrm{NL}^{-3}\right), \mathrm{S}$ is the concentration (colloid, bacteria or viruses) in the solid phase, the indexes of numbers 1 and 2, indicate kinetic sites 1 and 2, respectively, $\mathrm{D}$ is diffusion coefficient $\left(\mathrm{L}^{2} \mathrm{~T}^{-1}\right), v$ is pore velocity of water $\left(\mathrm{LT}^{-1}\right), \theta$ is total porosity $\left(\mathrm{L}^{3} \mathrm{~L}^{-3}\right), \rho_{b}$ is soil bulk density $\left(\mathrm{ML}^{-3}\right)$, and $\mathrm{S}$ is the concentration of bacteria adsorbed to the soil $\left.\left(\mathrm{NL}^{-3}\right)\right), \mathrm{K}_{\mathrm{att}}$ is the absorption rate of bacteria $\left(\mathrm{T}^{-1}\right)$ and $\mathrm{k}_{\mathrm{det}} \mathrm{is}$ the detachment rate of bacteria from soil particles $\left(\mathrm{T}^{-1}\right), \mathrm{t}$ is time, $\mu_{1}$ is inactivation of the bacteria in the liquid phase and $\mu_{\mathrm{s}}$ is inactivation of the bacteria in the solid phase. According to the sensitivity analysis, $\mathrm{K}_{\mathrm{att}}$ and $\mathrm{k}_{\mathrm{det}}$ parameters were used for calibration.

\section{Model Assessment}

In order to evaluate HYDRUS-2D model, from the comparison of the estimated and observed values of the model, salt and bacteria concentration drained from the column,Coefficient of Determination $\left(\mathrm{R}^{2}\right)$ Root Mean Square Error (RMSE), mean absolute error (MAE), Mean Absolute Error (MAE), Normalized-Root Mean Square Error (nRMSE) and Model Efficiently (EF) were obtained. Equations 6 to 9 show relationships for each of the parameters.

$$
\begin{gathered}
\text { MAE }=\frac{\sum\left|\mathrm{P}_{\mathrm{i}}-O_{\mathrm{i}}\right|}{\mathrm{n}} 5 \\
\text { RMSE }=\sqrt{\frac{\sum_{\mathrm{i}=1}^{\mathrm{n}}\left(\mathrm{P}_{\mathrm{i}}-\mathrm{O}_{\mathrm{i}}\right)^{2}}{\mathrm{n}}} 6 \\
\text { nRMSE }=\frac{\text { RMSE }}{\overline{0}} \times 1007 \\
\mathrm{EF}=1-\frac{\sum_{\mathrm{i}=1}^{\mathrm{N}}\left(\mathrm{P}_{\mathrm{i}}-\mathrm{O}_{\mathrm{i}}\right)^{2}}{\sum_{\mathrm{i}=1}^{\mathrm{N}}\left(\mathrm{P}_{\mathrm{i}}-\overline{\mathrm{O}}_{\mathrm{i}}\right)^{2}} 8
\end{gathered}
$$

Where, $\mathrm{P}$ is the estimated value, $\mathrm{Oi}$ is the observed value, $\bar{O}$ is the mean of observed values and $\mathrm{n}$ is the total number of observations. RMSE shows the difference between measured and simulated values, and the lower the index, the better model simulation. The optimum value of the efficiency of the model is equal to 1 for when the simulated and measured values are equal. MAE shows the deviation of the error and it is better when it is closer to zero. 


\section{Results and discussion}

The optimal calibration parameters are presented in Table (3). The residual moisture content and saturated moisture content in the matrix were greater than macropores and were 0.67 and 0.5 , respectively. The saturation hydraulic conductivity in macropores was higher than the matrix $\left(0.241 \mathrm{cmh}^{-1}\right)$. DIFW, DISPT, DISPL parameters in both matrix and macro phases had constant values.

Table 3. Values of the obtained parameters in reverse modeling in two matrix and macro phases.

\begin{tabular}{ccccccc}
\hline Parameter & $\theta_{\mathrm{r}}$ & $\theta_{\mathrm{s}}$ & $\mathrm{K}_{\mathrm{s}}\left(\mathrm{cmh}^{-1}\right)$ & DIFW $\left(\mathrm{cm}^{2} /\right.$ day $)$ & DISPT $(\mathrm{cm})$ & DISPL $(\mathrm{cm})$ \\
\hline Matrix & 0.067 & 0.50 & 0.015 & 0.05 & 0.05 & 0.05 \\
Macrospore & 0.057 & 0.48 & 0.241 & 0.05 & 0.05 & 0.05 \\
\hline
\end{tabular}

\section{Transfer of Bacteria}

Estimated parameters of kinetic attachment-detachment model of bacteria are presented in Table (4). The results showed that soil column treatments with a pore diameter of 1 and $2 \mathrm{~cm}$ had a lower attachment coefficient than the saturated column without macropores diameter. This attachment rate was observed both in the first and second attachment sites. Therefore, by increasing the diameter of macropore, more conditions were provided for the transmission of the bacteria and its lower attachment. According to poiseuille rule, a large amount of the entire flow passes through the larger pores, resulting in a greater amount of bacteria transferred from the soil. Bacterial detachment actually is risk to the return of pathogenic bacteria into the water and increase the risk of its contamination. Expressing the quantitative detachment of bacteria is necessary in determining the potential for transmission of bacteria. Field and laboratory observations showed bacterial detachment caused the trailing of breakthrough curve to be longer (USDA Natural Resources, 1999).

Jiang et al.(2007) on investigating several models reported that two-attachmentsites have higher performance. As it could be seen in Table $4, \mathrm{~K}_{\text {att }}$ value is more than 10 times of $\mathrm{k}_{\mathrm{det}}$, indicating that the attachment of the bacteria in the saturated columns is almost irreversible. Two-siteattachment parameters (Table 4) show well that soil columns have two kinetic attachment sites. The kinetic attachment site 1 is relatedto the salts with the same charge, such as sodium chloride, in which attachment is very rapid and detachment is very slow. The value of the attachment parameter at the kinetic site 1 in the soil column is between 0.0015 and 0.0065 . While, in this site the amount of detachment is zero. While in the attachment site 2, two processes of attachment and detachment arerapid. The attachment rate of bacteria in site 2 varies from 0.012 to 0.062 and the detachment rate ranges from 0.0042 to 0.0053 .

Table 4.The calibrated attachment-detachment model parameters of the bacteria

\begin{tabular}{ccccccc}
\hline Soil Columns & EC $\left(\mathrm{dsm}^{-1}\right)$ & Macrospore Diameter $(\mathrm{cm})$ & $\mathrm{K}_{\text {att1 }}$ & $\mathrm{K}_{\text {det1 }}$ & $\mathrm{K}_{\text {att2 }}$ & $\mathrm{K}_{\text {det2 }}$ \\
\hline A & 1 & 0 & 0.0065 & 0 & 0.0051 & 0.00042 \\
B & 1 & 1 & 0.0045 & 0 & 0.0052 & 0.00052 \\
C & 1 & 2 & 0.0055 & 0 & 0.0062 & 0.00053 \\
D & 2 & 0 & 0.0049 & 0 & 0.0052 & 0.00052 \\
E & 2 & 1 & 0.0035 & 0 & 0.0032 & 0.00055 \\
F & 2 & 2 & 0.0035 & 0 & 0.0031 & 0.00049 \\
G & 4 & 0 & 0.0025 & 0 & 0.0022 & 0.00051 \\
H & 4 & 1 & 0.0015 & 0 & 0.0022 & 0.00048 \\
I & 4 & 2 & 0.0021 & 0 & 0.0012 & 0.00042 \\
\hline
\end{tabular}

Figure 2 show that the effect of water salinity of $1 \mathrm{dsm}^{-1}$ (lowest salinity) was the same on the concentration of bacteria collected from soil columns at the beginning of leaching. However, by increasing leaching rate, the concentration of E. coli bacteria in the drained water collected from soil columns was decreased. With increasing salinity, the ionic strength of the soil solution is increased and the diffused double layer (DDL) is compressed. This action causes the bacteria to come closer to the surface of the soil particles and to overcome the forces of Van der Waals to absorb the bacteria on the surface of soil particles, therefore, with increasing solution concentration, transferring and leaching of bacteria in the soil decreases. It seems that in lower salinity, a wider transition took place in the preferential flow path and the arrival time was earlier. These results are consistent with the results of Liu et al. (2017). 


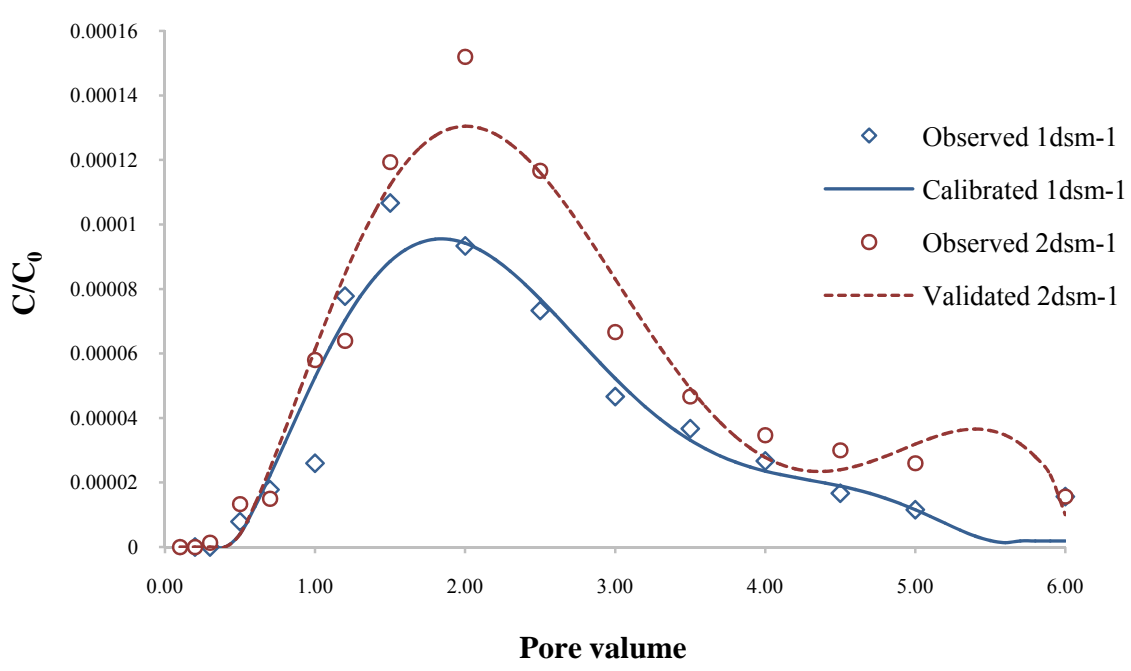

Figure 2. The measured breakthrough curve of the bacteria in the salinity treatment of soil column with electric conductivity of 2 ds / $\mathrm{m}$ (solid triangle) and soil column treatment with salinity of $1 \mathrm{ds} / \mathrm{m}$ (solid circle) and the calibrated (continuous line) and validated (dotted) breakthrough curve of the bacteria with HYDRUS-2D model.

The results of the evaluation of the calibrated breakthrough curve by the breakthrough resulted from validation showed that although the fitted data in the validation did not overlap with the measured values and there was an over-estimation in the simulation results, but the model was able to simulate the validation datawell. The results showed that the optimized attachment parameters of the model were less than the values determined in the laboratory. This suggests that the model, with no consideration for the flow in the coarsepores of the soil, greatly reduces the amount of attachment parameters in order to simulate the movement of the bacteria in the soil.The measured breakthrough curves of the bacteria in Fig. 3 show that the concentration of bacteria in the drained water quickly reached the peak concentration, and then the breakthrough curve has a large dispersion, which can be due to the presence of sites with different attachment and detachmentenergies in the soil. Although bacterial transfer experiments have been carried out under steady state, the presence of fluctuations and various peak points and drops in the breakthrough curve of the bacteria and the distribution of data indicate that there is a chemical and physical heterogeneity (Pang et al., 2008), because the soil columns have been formed from different levels of salinity that have different attachment and detachment abilities. It can also indicate the preferential flow paths for bacterial transmission. The peak point of the breakthrough curve and also the area under curve in the non-diameter treatment were higher and greater than that of treatment with diameter of $1 \mathrm{~cm}$, which indicates the occurrence of preferential flow and more consumed bacteria and as a result the high amount of itsoutput from the macropores, which caused the relative concentration of the bacteria reaches to about 0.00001 . The peak point of the breakthrough curve in the treatment with a macropores diameter is far below the control, and these curves are relatively symmetrical in shape, indicating a lack of preferential flow in them (Lee et al., 2018). The presence of macropores results in the rapid appearance of bacteria and the advance of the shape of breakthrough curve, while the diffusion from fine pores (from the inside of the aggregate) into coarse pores leads to delays in the release of the solutes and shrinkage of the shape of breakthrough curve (Esrahin et al., 2002). Therefore, in the importance of preferential flow to the transmission of microbes, it was found thatin higher ion strength, the effect of preferential flow increases even if overall bacterial transmission is reduced (Wang et al., 2013). Morales et al.(2014), generally fitted two die-off and attachment / detachment indices as a particular variable in the tailing stage, to better test the model. Apart from the fitting method, the attachment rate that fitted with the model was higher in sandy and loamy sandy soils than clay soils. Also, these results were consistent with the report of Unc and Goss(2003). they showed the preferential flows in the movement and purification of bacteria in the soil. The soil's ability to purify the bacteria in the macropores decreased (Sahraei and Mahboubi, 2009). 


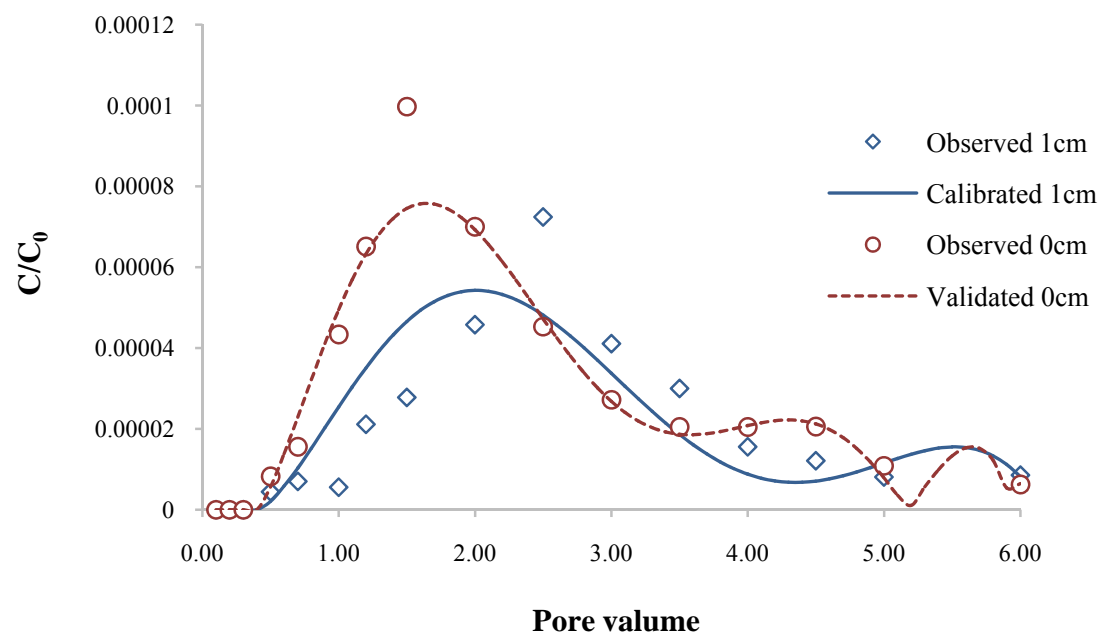

Figure 3. The measured breakthrough curve of the bacteria in without macroporous diameter treatment (solid triangle) and the soil column treatment with a diameter of $1 \mathrm{~cm}$ (solid circle) and the calibrated (continuous line) and validated (dotted point) breakthrough curve of the bacteria with HYDRUS-2D Model.

\section{Retention of Bacteria}

The retention of bacteria in saturated soils can be as a result of various mechanisms such as attachment to soil particles, physical purification and sedimentation. The measured and estimated curve of bacterial retention in the soil profile is presented in Fig. 4. As it could be seen, the measured retention curve in the macropores of soil profile and estimated in the HYDRUS-2D model has almost a linear shape, while the measured and fitted retention rate in the soil matrix has an exponential shape. Also, the results showed that most of the bacteria were retained in the surface layers of the soil and the amount of retention decreased with increasing depth.The fitted results of the retained bacteria in the macropores was a little greater than the measured concentration, while the results of the measured and fitted data of matrix had a high overlap, according to the results, we can say that the model has a good prediction of the concentration of the profile. The results show that if the bacteria are leached from the soil surface and transferred to depths more than $10 \mathrm{~cm}$, the rate of leaching and its removal from the soil by preferential flow and the transfer of salts is very high and it quickly causes groundwater contamination. Results of homogenous transfer experiments of Wang et al. (2013) showed that the retention of E. coli and coliphage increased with increasing ionic strength of the solution, while the amount of bacteria in the fine sand was higher than that of coarse sand.This microbial transmission behavior was well estimated by numerical simulations. In addition to macropores and matrix, they considered that the retention has been occurred in the interfaces between macropores and matrix. Their results showed that the transfer of bacteria in the preferential flow path was accompanied by a decrease in the ion strength of the solution in the multi-pulsebreakthrough curve, which was strongly correlated with the initial retention of the macropores-matrix interfaces.Jiang et al.(2007) showed that the length of the column had no significant effect on the peak concentration of E. coli or total recovery of sodium, indicating bacterial retention in the upper layer of the sand column. Farhangi et al.(2012) showed that the role of soil surface layer was prominent in bacterial purification, but the presence of preferentialflows, especially at early times, led to the transfer of bacteria to the second layer. 


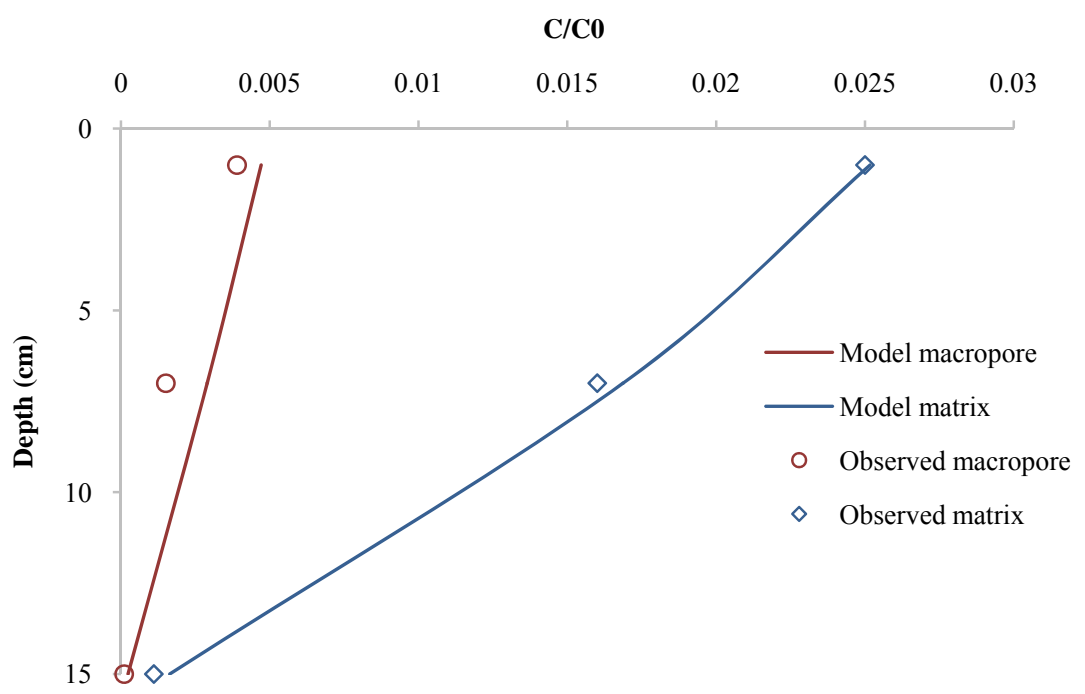

Figure 4. The amount of measured bacteria in macropores (solid circle) and the matrix of soil profile (solid triangles), and estimated by the attachment / detachmentmodel of the bacteria in the macropore (continuous line) and the matrix (dotted line) with HYDRUS-2 D model.

\section{Evaluation of Model Efficiency}

Calibration attempts to minimize model errors. Therefore, calibration involves modifying the values of the model parameters and comparing the expected output with observational data until a given target function is obtained. The accuracy of the model was evaluated by $\mathrm{R}^{2}$, RMSE, nRMSE, MAE and EF indices, the results of which are presented in Table 5. The results show that the model is simulated the flow very well. The results of the evaluation indices showed that the calibration of the model in the breakthrough curve and soil profile with coefficient of determination $\left(\mathrm{R}^{2}\right)$ of 0.97 and 0.99, RMSE andnRMSE of 13.06 and 0.31 , andlow absolute mean of error is acceptable. The efficiency coefficient of the model in validation was also found to be appropriate. Validation of model results is essential for increasing user trust in predictive model capability. The values of the coefficient of determination and nRMSE are 0.95 and 8.1 for the breakthrough curve of 0.89 and 1.22 for the soil profile, respectively, which indicates the proper performance of the model during the validation period. RMSE values in Table 5 show the model errors in estimating the breakthrough curve and retention the bacteria in the soil profile. The closer RMSE to zero, the model estimation is better. These results indicate that the model has a good estimation of the breakthrough curve and the retention of bacteria in the soil. According to the results of the evaluation parameters, validation is of appropriate acceptability and its results are acceptable, which indicates the accuracy of the implementation of the model.

Table 5. Results of error estimation indices and evaluation, calibration and validation of the model

\begin{tabular}{|c|c|c|c|c|c|}
\hline Model & $\mathrm{R}^{2}$ & RMSE & nRMSE & MAE & $\mathrm{EF}$ \\
\hline \multicolumn{6}{|c|}{ Calibrated } \\
\hline Breakthroughcurve & 0.97 & 0.00037 & 13.06 & $1.36 \mathrm{E}-07$ & 0.92 \\
\hline Soil profile & 0.99 & 0.025 & 0.31 & 0.00065 & 0.98 \\
\hline \multicolumn{6}{|c|}{ Validated } \\
\hline Breakthroughcurve & 0.95 & 0.00021 & 8.01 & 0.0000042 & 0.95 \\
\hline Soil profile & 0.89 & 0.012 & 1.22 & 0.00012 & 0.91 \\
\hline
\end{tabular}

\section{Discussion and conclusion}

The results showed that the retention of bacteria in all soil columns was much greater than the transferred amount. The amount of bacteria observed in the drained water was $2-3 \%$. In other words, more than $96 \%$ of the bacteria were retained in the soil column, indicating high soil power in bacterial purification. This issue is being discussed from a variety of dimensions. The retention and refinement of the bacteria can indicate the more ability of the sandy loam soils to refine the bacteria due to the weaker structure and smaller pores, in other words, the bacteria are physically captured and trapped in the fine pores of sandy loam soil. On the other hand, the bacteria are trapped in the pores because of the lower velocity of water in the fine pores and the accumulation of bacteria, which closes the path of movement of other bacteria, and results in more bacteria being refined.On the other hand, the role of sodium chloride in retaining bacteria in the soil is due to the high electrolyte content. This is important, along with the soil's ability to remove pathogenic microbes in the process of disinfection and treatment of sewages. On the other hand, parts of the bacteria transferred along the path of preferential flows in high salinities have disappeared, which confirms the role of salinity in eliminating 
microbes and reducing water contamination. As the depth of soil increased, the pollutant concentration also decreased, indicating the effect of soil on the purification of microbial contaminants as a normal filter. The obtained results showed the effectiveness of it in different aspects of the study. It seems that in the inverse method, the attachment and detachment coefficients of the bacteria at the surface of the soil colloids were introduced into the model during the simulation process and the simulation was performed based on the amount and attachment and detachment capacity of the bacteria. Although the bacterial transmission is facilitated in salinity, the results of this study showed that increased ionic strength of the soil solution increased the amount of bacterial purification that could be effective in controlling groundwater contamination with saline water management, so that the least transition has taken place and the conditions for the use of unconventional water sources are also created, without the environmental problem threatening the risk of groundwater pollution.

\section{References}

[1] Ali Ayyayi M. 1997. Description of Soil Chemical Analysis Methods, Vol. 2, No. 1024, Water and Soil Research Institute. (In Persian).

[2] Connie R., Mahon, Donald C., Lehman, George Manuselis. Textbook of diagnostic microbiology, 2011Chapter 1, page 14.

[3] Ersahin S, Papendick RI, Smith JL, Keller CK, Manoranjan VS. 2002. Macropore transport of bromide as influenced by soil structure differences. Geoderma 108: 207-1223 Crossref.

[4] Farhangi MB, Mosdeghi MR, Safari AA, and Mahboubi AA. 2012. E. coli bacteria from cattle manure in the soil released the unsaturated farm. Journal of Science and Technology of Agriculture and Natural.

[5] Farrokhian Firouzi A, Homaee M, Klumpp E, Kasteel R, and Tappe W. 2015. Bacteria Transport and Retention in intact calcareous soil columns under saturated Flow conditions. J. Hydrol. Hydromech., 63 (2): 102-109.

[6] Feng G, Zhang Z, Wan C, Lu P, and Bakour A. 2017. Effects of saline water irrigation on soil salinity and yield of summer maize (Zea mays L.) in subsurface drainage system. Agricultural Water Management, 193, pp.205-213.

[7] Foppen J, Schijven J. 2006. Evaluation of data from the literature on the transport and survival of Escherichia coliand thermotolerant coliforms in aquifers under saturated conditions. Water Research 40, 401-426.

[8] Guzman J. A, Fox GA, Malone RW, and Kanwar R. 2010.Escherichia colitransport from surface-applied manure to subsurface drains through artificial biopores. J. Environ. Qual. 38(6): 2412-2421.

[9] Hasanpour Darvishi, H. 2010. Investigating the effect of saline water on quantitative and qualitative traits of seeds in medicinal herbs. Journal of Agronomy and Plant Breeding. 6 (2): 13-20 (In Persian).

[10] Jackwood RW. 2013. Predicting Fate and Transport of Fecal Bacteria through Soils Using an Advection-Dispersion Model. The University of Toledo.

[11] Kim k. Owens, and G. Nasido R. 2009. Heavy metal distribution, bioaccessibility, and phytoavailability in long-term contaminated soils from Lake Macquarie, Australia. 47(2):115-129.

[12] Li B, Pales AR, Clifford HM, Kupis S, Hennessy S, Liang WZ, Moysey S, Powell B, Finneran KT, Darnault CJ. Preferential Flow in the Vadose Zone and Interface Dynamics: Impact of Microbial Exudates. Journal of Hydrology. 2017 Dec 28.

[13] Liu HF, Genard M, Guichard S. and Bertin N. 2007. Model-assisted analysis of tomato fruit growth inrelation to carbon and water fluxes. Journal of Experimental Botany, 58(13): 3567-3580.

[14] Mamilov A, Dilly OM, Mamilov,Inubushi S. 2004. Microbial ecophysiology ofdegrading aral sea wetlands: consequences for Ccycling. Soil Sci. Plant Nutr. 50:839-842.

[15] Morales I, Atoyan JA, Amador JA, Boving T. 2014. Transport of Pathogen Surrogates in Soil Treatment Units: Numerical Modeling. Water 6, 818-838.

[16] Pang L.Macleod M, Aislabie J, Simunek J, Close M, and Hector R. 2008. Modeling transport of microbes in tenundisturbed soils under effluent irrigation. Vadose Zone J. 7: (97-111).

[17] Pang L, Simunek J. 2006. Evaluation of bacteria-facilitated cadmium transport in gravel columns using the HYDRUS colloid-facilitated solute transport model. Water resources research 42.

[18] Safadost A, Mahbubi AA, Mossadeghi MR, Khodkaramian G, Heydari A. 2012 Movement of Escherichia coli bacteria in soil columns under different flow conditions and temperatures. Journal of Water and Soil Science, Science and Technology of Agriculture and Natural Resources 15, 183-197 (In Persian).

[19] Sahraei N, Mahboobi AA. 2009. Investigating the Effect of Soil and Organic Fertilizer Building on the Movement of Escherichia coli in Soil Columns, Twelfth National Conference on the Health of Iran, Shahid Beheshti University of Medical Sciences, Tehran, Iran. (In Persian).

[20] Schijven J, and Simunek J. 2002. Kinetic modeling of virus transport at field scale. J. Contaminate Hydrol. 5 (1-2):113-135.

[21] Schulin R, Wierenga PJ, Flühler H, and Leuenberger J. 1987. Solute transport through a stony soil. Soil Sci. Soc. Am. J. 51: 36-42.

[22] Sebben Megan L, and Adrian D. Werner. 2016. A modelling investigation of solute transport in permeable porous media containing a discrete preferential flow feature." Advances in Water Resources 94 (2016): 307-317.

[23] Simunek J, Šejna M, andVan Genuchten M. 1999. The HYDRUS-2D Software Package for Simulating the Two-Dimensional Movement of Water, Heat, and Multiple Solutes in Variably-Saturated Media. U.S. salinity agricultural research service laboratory Riverside, California.

[24] Simunek J, Jarvis N, Van Genuchten M, and Garden A. 2003. Review and comparision of models for describing non-equilibrium and preferential flow andtransport in the vadose zone. Journal of hydrology. 272: 14-35.

[25] Singh P, and Kanwar R. 1991. Preferential solute transport through macropores in largeundisturbed saturated soil columns. J. Environ. Qual. 20: 295-300.

[26] Tufenkji N. 2007. Modeling microbial transport in porous media: Traditional approaches and recent developments.Adv. Water Resour. 30: $1455-1469$.

[27] Unc A, and Goss MJ. 2003. Movement of faecal bacteria through the vadose zone. Water, Air, and Soil Pollution 149:1-4. 327-337.

[28] USDA Natural Resources Conservation Service. 1999. Soil taxonomy. A basic system of soil classification formaking and interpreting soil surveys. 2nd ed., USDA. S.C.S. Agric. U. SW. Gov. Print office, Washington, DC.

[29] Wang Y, Bradford SA, and Simunek J. 2014. Physicochemical Factors Influencing the Preferential Transport of Escherichia coli in Soils. Gsvadzone. 13:1-10.

[30] Wang Y, Bradford SA, Simunek J. 2013. Transport and fate of microorganisms in soils with preferential flow under different solution chemistry conditions. Water resources research 49, 2424-2436.

[31] Xing L, Chunhui G, Dandan JL, Walker Q, Huang PC. 2017. Survival of Escherichia coli O157:H7 in various soil particles: importance of the attached bacterial phenotype. Biology and Fertility of Soil. Volume 53, Issue 2, pp 209-219. 